\title{
RELATIONSHIP BETWEEN A RANGE OF TISSUE TEMPERATURE AND LOCAL OXYGEN UPTAKE IN THE HUMAN FOREARM. III. CHANGES OBSERVED AFTER ANAEROBIC WORK, IN THE POSTEXERCISE PERIOD * $\dagger$
}

\author{
By DAVID I. ABRAMSON, SAMUEL TUCK, JR., YVONNE BELL, CAROLYN \\ BURNETT AND HABIB REJAL
}

\author{
(From the Departments of Physical Medicine and Rehabilitation and Medicine, University of \\ Illinois College of Medicine, Chicago, Ill.)
}

(Submitted for publication December 24, 1958; accepted March 5, 1959)

It is generally accepted that a blood flow debt is incurred in active muscles which is repaid in the postexercise period through the production of a hyperemia, the magnitude of the latter being related to the concentration of local metabolites at the end of the period of work (1-3). However, it has been shown by Barcroft, Dornhorst, McClatchey and Tanner (2) that increasing the blood available to the forearm by release of sympathetic vasoconstrictor tone had no effect upon the size or rate of repayment of the blood flow debt. Patterson and Shepherd (3) have reported similar results after the amount of metabolically available blood passing through the tissues was doubled by means of arterial infusion of vasodilator substances. Such evidence has been interpreted as indicating that augmenting the resting circulation alone has no influence on the rate of inactivation or removal of metabolites formed in exercising muscles.

The purpose of the present investigation was to determine whether or not an increase in blood flow and tissue temperature produced by local application of heat had any effect upon the magnitude of the oxygen debt incurred in the forearm during a short period of anaerobic work. This approach was undertaken because of the data previously obtained indicating that the resting oxygen uptake (4) and the oxygen debt resulting from five minutes of arterial occlusion (5) were increased by raising tissue temperatures and decreased by low-

* This investigation was supported in part by the Research Grant H-2568 from the National Institutes of Health, United States Public Health Service, Bethesda, Md.

$\dagger$ This paper was presented before the Thirty-first Annual Meeting of the Central Society for Clinical Research, Chicago, Illinois, October 31 and November 1, 1958. ering them. Anaerobic exercise was used in order to ascertain accurately the entire oxygen debt through a study of the excess oxygen repayment in the postexercise period.

\section{METHOD}

Fourteen experiments were performed on 14 healthy subjects between the ages of 21 and 34 years. The duration of the period of observation averaged six hours, during which time food intake was limited to one or two small chocolate bars.

Utilizing the same technique and environmental conditions described in a previous paper (4), the following measurements were made: blood flow, oxygen content of venous blood and muscle, ${ }^{1}$ subcutaneous tissue and skin temperatures, all obtained from the upper two-thirds of the forearm; blood pressure and pulse rate readings, using the opposite limb; and determinations of rectal temperature. In all instances blood samples were collected from a vein in the antecubital fossa which had no obvious superficial tributaries and which appeared to drain deep tissues primarily. The polyethylene catheter was passed far enough into the vessel, in the direction of the hand, so that its tip lay in the mass of tissue enclosed by the plethysmograph.

Plan of experiment. After the segment of forearm was placed in the plethysmograph and the openings made watertight (6), the machine was filled with water at either $45^{\circ}$ or 28 to $30^{\circ} \mathrm{C}$. (bath temperature). Then the subject was instructed to compress a blood pressure bulb 60 times in 30 seconds, to raise the pressure in a five gallon bottle to a level of 50 to $80 \mathrm{~mm}$. $\mathrm{Hg}$, the height reached depending, in part, upon his state of physical fitness. During this time blood was prevented from entering the forearm through the application of an arterial occlusion pressure to the arm. No records were made in the postexercise period, since the purpose of the initial trial was to acquaint the subject with the type of exercise used in the study.

After a period of more than 90 minutes of exposure

1 The muscle thermocouple was inserted perpendicularly to the skin into the brachioradialis muscle mass for an average distance of $4.1 \mathrm{~cm}$. (range 2.1 to $5.3 \mathrm{~cm}$.). 


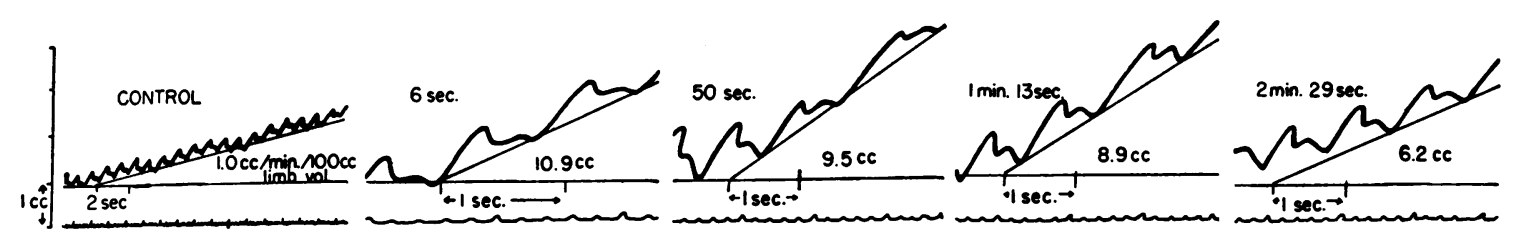

A

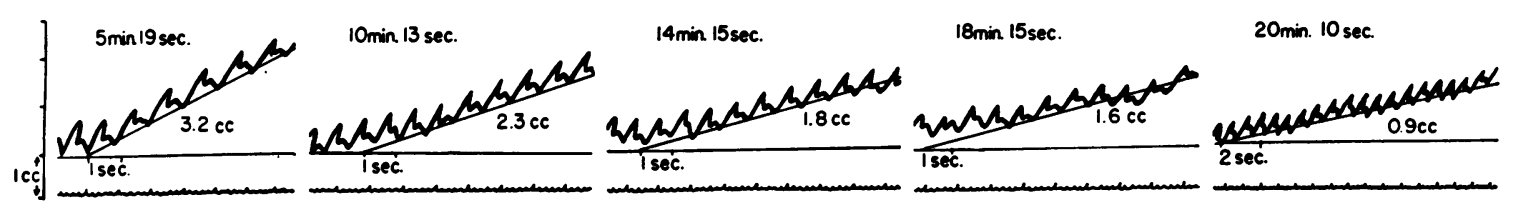

B

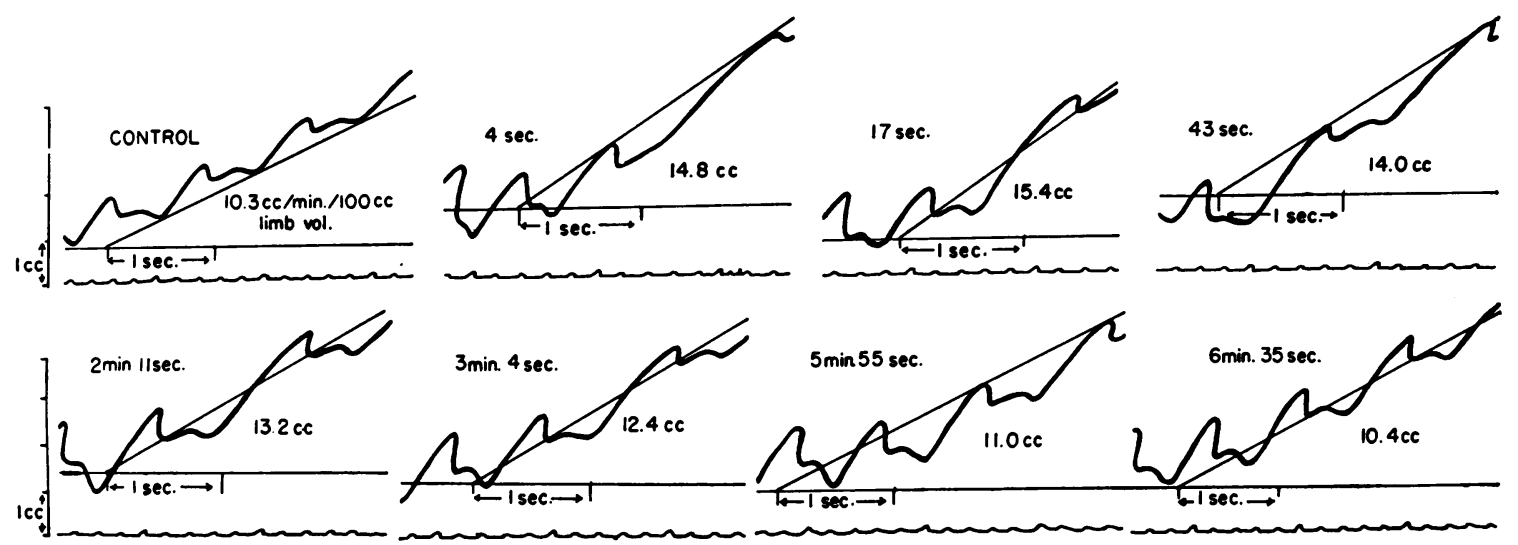

Fig. 1. Forearm Blood Flow Curves Obtained on Subject J. F. Before and After One-Half Minute of ANAEROBIC EXERCISE

$\mathrm{A}=$ control and postexercise readings collected at a bath temperature of $30^{\circ} \mathrm{C} . \quad \mathrm{B}=$ control and postexercise readings collected at a bath temperature of $45^{\circ} \mathrm{C}$. The calculated blood flow in ml. per minute per $100 \mathrm{ml}$ l limb volume and the time in the postexercise period are indicated for each determination. Calibration scale, in cc. divisions, is to the left of the curve. An arterial occlusion pressure was maintained at the wrist during blood flow recordings.

of the forearm to the maintained water temperature, control readings for blood flow, venous oxygen content and tissue temperatures were collected. Following this another one-half minute period of anaerobic exercise was performed, during which time the stopcock attached to the catheter in the vein remained open to permit drainage of blood out of the vessel. Immediately after the termination of the exercise and the release of the arterial occlusion pressure on the arm, blood flow readings (Figure 1), venous blood samples and temperature recordings were obtained at rapid intervals, generally three or four in the first minute of the postexercise period, two in the second and five spaced over the next 10 to 20 minutes. In every instance care was taken not to draw a blood sample at the same time as blood flow was being recorded (5).

After the various readings had returned to the preexercise baseline, the bath temperature was changed to either the higher or the lower one, depending upon which had been used initially 2 and the procedure already de-

2 The order in which the experiments were performed in no way affected the results. scribed was repeated. The level to which the pressure was raised in the five gallon bottle by the exercise was kept the same as in the previous trials.

\section{RESULTS}

From the venous oxygen determinations and the derived figures for oxygen content of arterial blood, oxygen arteriovenous difference was obtained for the resting and for the postexercise periods. On the basis of these figures and the readings of blood flow, oxygen uptake was then calculated, using the Fick principle (7).

From the data, graphs were constructed for postexercise blood flow, oxygen arteriovenous difference and oxygen uptake (Figures 2 and 3 ). In each instance the values were plotted against time in minutes, with the baseline being derived from three to five pre-exercise control readings and from a similar number obtained after the effect of 
the work had completely disappeared. In the case of blood flow and oxygen uptake, the area under the curve and above the baseline was then measured by means of a planimeter and expressed in proper units by multiplying the derived figure by an appropriate factor. The resulting value was considered to represent the total response to the exercise and the one-half minute period of arterial occlusion.

\section{Systemic changes}

Rectal temperatures (Table I), pulse rates and blood pressure readings showed no consistent alterations at the higher, as compared with the lower, bath temperature; nor were the changes produced by exercise any different under the two experimental conditions. Immediately after termination of the work there was an average rise of $9 \mathrm{~mm}$. $\mathrm{Hg}$ in systolic pressure and $3 \mathrm{~mm}$. $\mathrm{Hg}$ in diastolic pressure which lasted for from two to six minutes. The alterations in pulse rate were inconstant.

\section{Results obtained under resting conditions}

Examination of Table I reveals that the average values for oxygen capacity, calculated arterial oxygen content, resting venous oxygen and resting blood flow at a bath temperature of $45^{\circ} \mathrm{C}$. were approximately the same as the figures reported in previous papers $(4,5)$. The difference observed between the average resting oxygen uptake at a bath temperature of $45^{\circ}$ and that at 28 to $30^{\circ}$ (Table I) was found to be statistically significant, with a $\mathrm{p}<0.01(8)$.

\section{Blood flow responses to anaerobic work}

At both bath temperatures the blood flow curve in the postexercise period manifested an initial sharp rise followed by a sharp fall, and

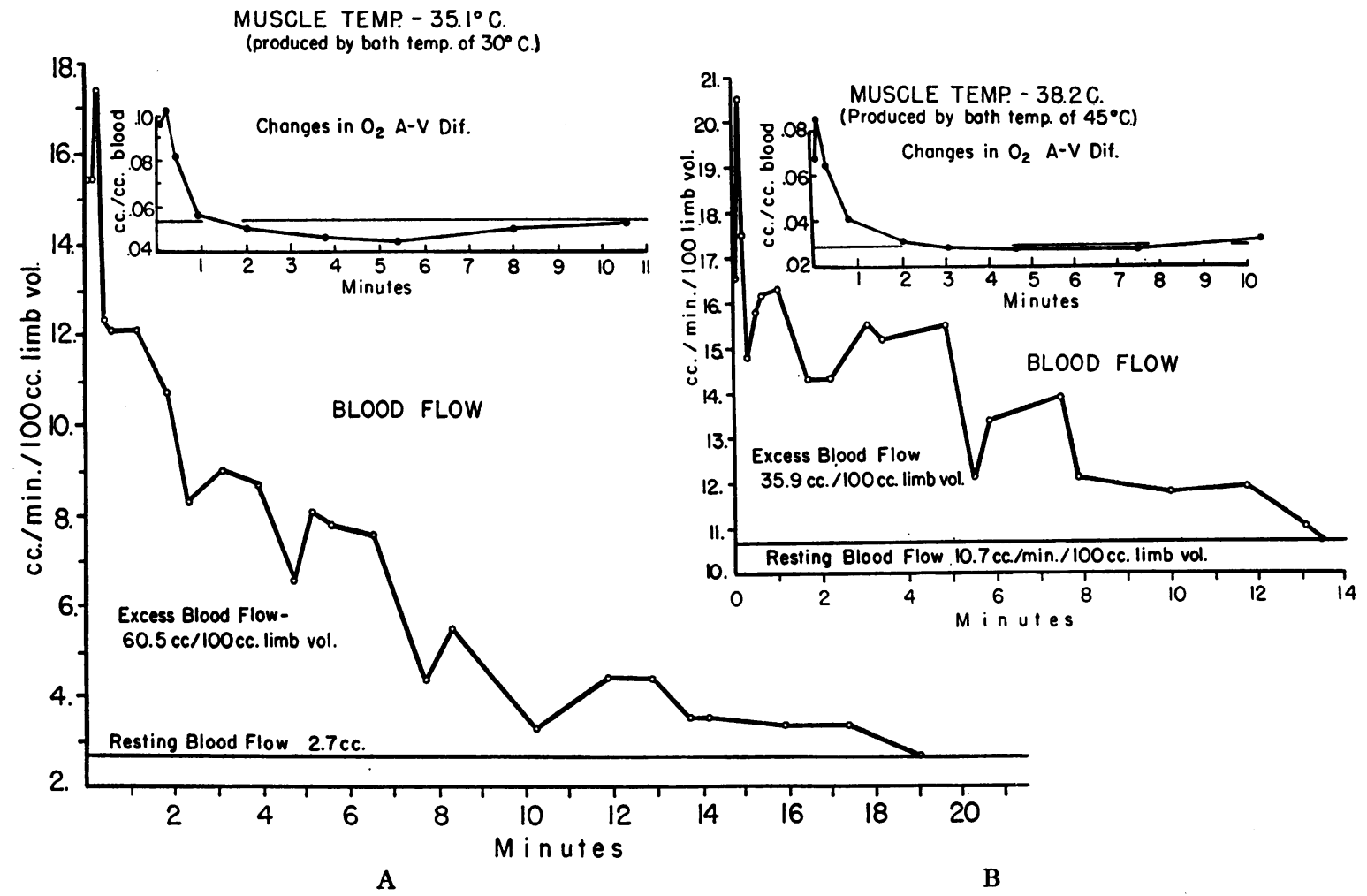

Fig. 2. Graphs of Blood Flow and of Oxygen Arterionenous Differences Obtained in the Postexercise Period on Subject E. P.

$\mathrm{A}=$ bath temperature of $30^{\circ} \mathrm{C} . \mathrm{B}=$ bath temperature of $45^{\circ} \mathrm{C}$. A negative deflection follows the positive one in the graph for oxygen arteriovenous difference obtained at a bath temperature of $30^{\circ} \mathrm{C}$. This is not observed at a bath temperature of $45^{\circ} \mathrm{C}$. 


\section{OXYGEN UPTAKE}

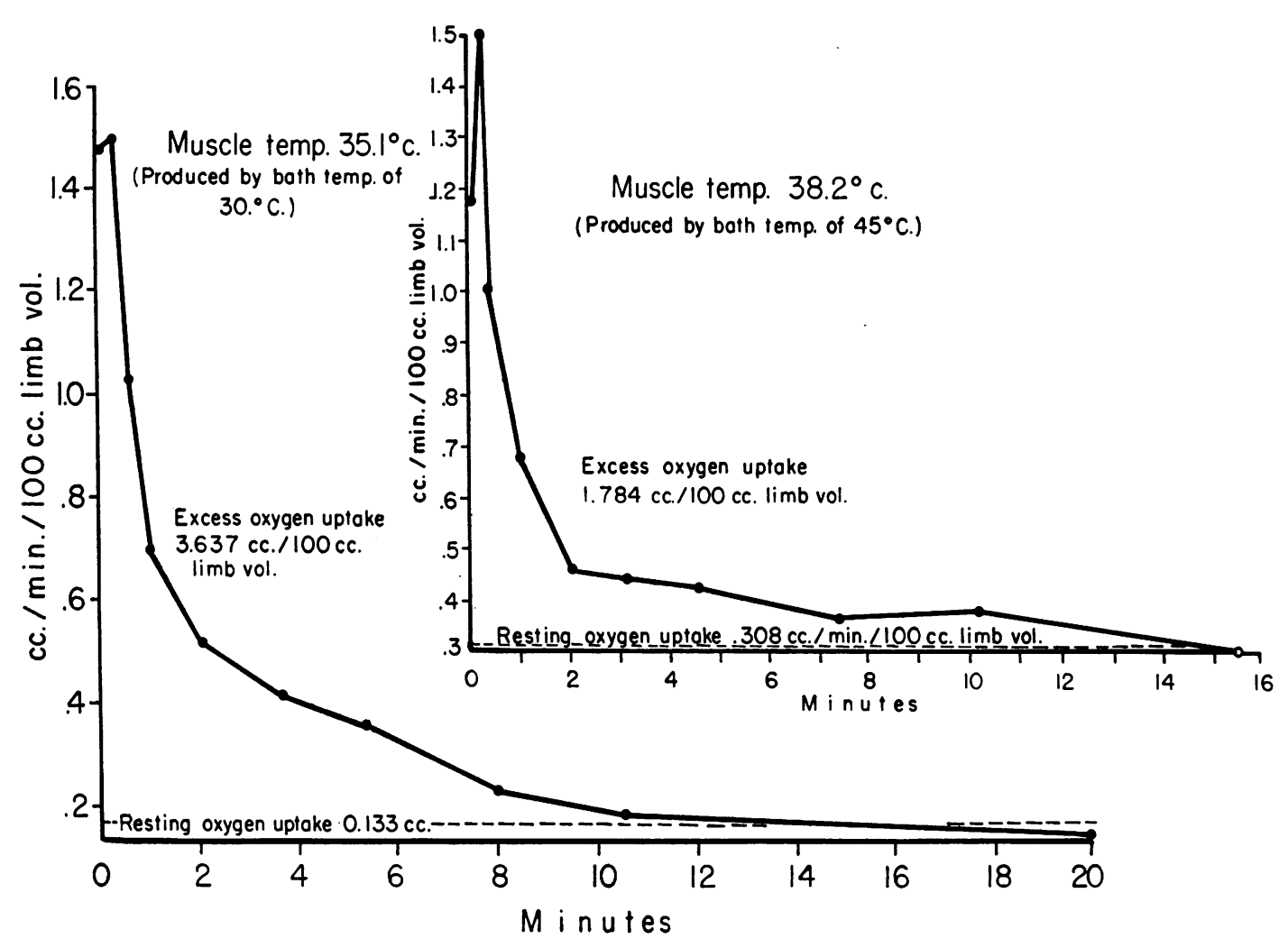

Fig. 3. Graph of Oxygen Uptake Obtained in the Postexercise Period on Subject E. P.

Lower curve $=$ bath temperature of $30^{\circ} \mathrm{C}$. Upper curve $=$ bath temperature of $45^{\circ} \mathrm{C}$. Graphs are based on blood flow and oxygen arteriovenous differences as depicted in Figure 2.

then a more gradual drop to the baseline (Figure $2)$. The peak of the response occurred early in the postexercise period (average of 15 seconds at the higher bath temperature and 22 seconds at the lower). The actual maximal increase, in excess of the resting level, was generally larger at the lower bath temperature (average of $9.1 \mathrm{ml}$. per minute per $100 \mathrm{ml}$. limb volume, as compared with $6.9 \mathrm{ml}$. for the higher bath temperature). Furthermore, the average duration of the postexercise excess blood flow response was longer, 902 seconds as compared with 538 seconds for the higher bath temperature, a difference which was found to be statistically significant $(p<$ 0.01 ). Finally, the total augmentation in blood flow, in excess of the resting level, in the postexercise period was also greater at the lower bath temperature except in four cases. Of the latter, in two the response was approximately the same, while in the remaining two it was greater at the higher bath temperature. The difference between the two sets of readings (Table I) was found to be statistically significant, with a $\mathrm{p}<0.01$.

\section{Changes in oxygen arteriovenous difference in postexercise period}

Consistently at both bath temperatures definite increases in oxygen arteriovenous difference were noted in the initial portion of the postexercise period. The resulting curve (Figure 2) consisted of a sharply rising slope, followed by a sharply falling one, with the baseline being reached at an average of 124 and 175 seconds after termination of exercise for the lower and higher bath temperatures, respectively. The greatest increase in oxygen arteriovenous difference occurred early (average of 19 seconds for the lower and 16 seconds for the higher bath temperature) the actual av- 
erage increase, in excess of the control level, being $0.058 \mathrm{ml}$. per $\mathrm{ml}$. of blood for the former and $0.082 \mathrm{ml}$. per ml. of blood for the latter.

In every instance in the case of the lower bath temperature, the positive deflection, described above, was followed by a negative one (Figure 2 ), indicating that the oxygen arteriovenous differences were now smaller than those observed in the control period. Such a change was also noted three times at the higher bath temperature. With regard to the lower bath temperature, the negative deflection returned to the baseline after an average of 710 seconds, while in the three instances in which such an alteration occurred at the higher bath temperature, this took place at an average of 432 seconds.

\section{Changes in oxygen uptake in postexercise period}

Under both experimental conditions, the postexercise oxygen uptake curve manifested a rapid rise and a rapid fall, followed by a more gradual drop to the baseline (Figure 3). The peak of the

TABLE I

Effect of different bath temperatures on oxygen uptake of the forearm following anaerobic work

\begin{tabular}{|c|c|c|c|c|c|c|c|c|c|c|c|c|c|c|}
\hline & & & & & Bat & h tempe & rature- & $-45^{\circ} \mathrm{C}$. & & & & & & \\
\hline 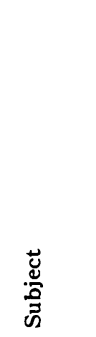 & 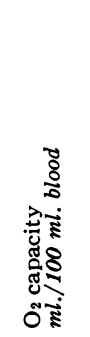 & 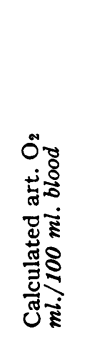 & 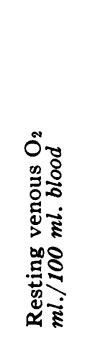 & 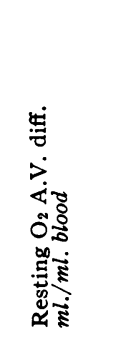 & 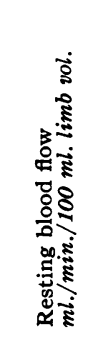 & 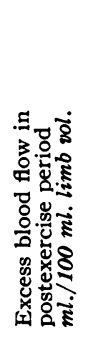 & 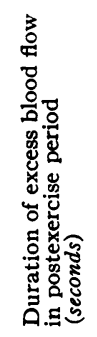 & 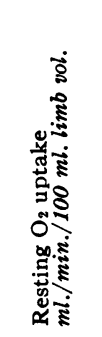 & 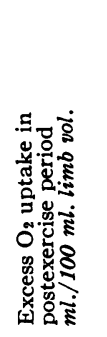 & 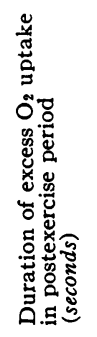 & $\frac{\Xi}{\frac{\pi}{\omega}}$ & 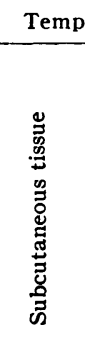 & 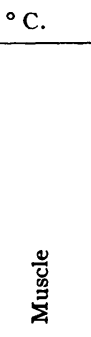 & $\begin{array}{l}\text { 芯 } \\
\text { 幽 }\end{array}$ \\
\hline $\begin{array}{l}\text { P. S. } \\
\text { G. W. } \\
\text { E. P. } \\
\text { G. P. } \\
\text { S. M. } \\
\text { N. D. } \\
\text { M. I. } \\
\text { N. S. } \\
\text { G. L. } \\
\text { S. S. } \\
\text { J. T. } \\
\text { J. F. } \\
\text { A. F. } \\
\text { C. P. }\end{array}$ & $\begin{array}{l}21.12 \\
19.84 \\
19.39 \\
19.24 \\
19.13 \\
23.82 \\
16.60 \\
22.22 \\
22.50 \\
21.25 \\
20.43 \\
22.37 \\
20.34 \\
18.15\end{array}$ & $\begin{array}{l}20.34 \\
19.09 \\
18.65 \\
18.50 \\
18.39 \\
22.99 \\
15.91 \\
21.42 \\
21.69 \\
20.48 \\
19.66 \\
21.56 \\
19.57 \\
17.43\end{array}$ & $\begin{array}{l}18.44 \\
16.92 \\
15.75 \\
13.23 \\
12.74 \\
20.12 \\
12.83 \\
18.95 \\
14.93 \\
15.49 \\
18.09 \\
18.01 \\
17.95 \\
16.15\end{array}$ & $\begin{array}{l}0.0190 \\
0.0217 \\
0.0289 \\
0.0527 \\
0.0564 \\
0.0286 \\
0.0308 \\
0.0247 \\
0.0675 \\
0.0498 \\
0.0156 \\
0.0354 \\
0.0162 \\
0.0127\end{array}$ & $\begin{array}{r}7.5 \\
6.2 \\
10.7 \\
3.4 \\
6.2 \\
10.5 \\
8.8 \\
9.9 \\
8.9 \\
6.9 \\
6.2 \\
10.0 \\
8.0 \\
8.3\end{array}$ & $\begin{array}{r}31.7 \\
20.0 \\
35.9 \\
2.3 \\
10.3 \\
3.5 \\
30.6 \\
34.7 \\
15.4 \\
3.6 \\
25.0 \\
20.3 \\
20.8 \\
37.8\end{array}$ & $\begin{array}{r}510 \\
360 \\
807 \\
175 \\
327 \\
186 \\
615 \\
813 \\
552 \\
272 \\
1,020 \\
530 \\
330 \\
1,030\end{array}$ & $\begin{array}{l}0.142 \\
0.134 \\
0.309 \\
0.179 \\
0.350 \\
0.300 \\
0.271 \\
0.244 \\
0.601 \\
0.344 \\
0.097 \\
0.354 \\
0.130 \\
0.105\end{array}$ & $\begin{array}{r}1.468 \\
2.078 \\
1.784 \\
.453 \\
.479 \\
1.475 \\
1.493 \\
3.617 \\
1.765 \\
.910 \\
.545 \\
.645 \\
2.642 \\
1.840\end{array}$ & $\begin{array}{l}565 \\
340 \\
929 \\
170 \\
146 \\
302 \\
357 \\
794 \\
615 \\
208 \\
272 \\
380 \\
567 \\
701\end{array}$ & $\begin{array}{l}40.9 \\
40.6 \\
41.5 \\
42.5 \\
40.2 \\
40.5 \\
42.3 \\
40.8 \\
42.0 \\
40.1 \\
42.0 \\
41.4 \\
41.1\end{array}$ & $\begin{array}{l}39.4 \\
39.6 \\
40.1 \\
42.5 \\
40.2 \\
39.7 \\
40.1 \\
39.5 \\
39.4 \\
41.1 \\
40.1 \\
40.1 \\
40.7 \\
40.6\end{array}$ & $\begin{array}{l}39.0 \\
38.2 \\
38.2 \\
39.3 \\
38.1 \\
38.6 \\
37.7 \\
37.8 \\
37.2 \\
37.8 \\
38.3 \\
38.6 \\
38.2 \\
38.3\end{array}$ & $\begin{array}{l}36.6 \\
37.4 \\
36.9 \\
37.5 \\
37.4 \\
37.1 \\
37.6 \\
37.6 \\
37.8 \\
37.7 \\
37.6\end{array}$ \\
\hline Mean & 20.46 & 19.69 & 16.40 & 0.0329 & 8.0 & 20.8 & 538 & 0.254 & 1.514 & 453 & 41.2 & 40.2 & 38.2 & 37.4 \\
\hline Standa & d error & & & & \pm 0.55 & \pm 3.33 & & \pm 0.037 & \pm 0.240 & & & & & \\
\hline & & & & & Bath & temper & ture -2 & $8-30^{\circ} \mathrm{C}$ & & & & & & \\
\hline $\begin{array}{l}\text { P. S. } \\
\text { G. W. } \\
\text { E. P. } \\
\text { G. P. } \\
\text { S. M. } \\
\text { N. D. } \\
\text { M. I. } \\
\text { N. S. } \\
\text { G. L. } \\
\text { S. S. } \\
\text { J. T. } \\
\text { J. F. } \\
\text { A. F. } \\
\text { C. P. }\end{array}$ & $\begin{array}{l}21.12 \\
19.84 \\
19.39 \\
19.24 \\
19.13 \\
23.82 \\
16.60 \\
22.22 \\
22.50 \\
21.25 \\
20.43 \\
22.37 \\
20.34 \\
18.15\end{array}$ & $\begin{array}{l}20.34 \\
19.09 \\
18.65 \\
18.50 \\
18.39 \\
22.99 \\
15.91 \\
21.42 \\
21.69 \\
20.48 \\
19.66 \\
21.56 \\
19.57 \\
17.43\end{array}$ & $\begin{array}{r}13.63 \\
12.48 \\
13.25 \\
10.11 \\
11.98 \\
15.81 \\
9.44 \\
12.08 \\
11.21 \\
11.73 \\
13.76 \\
12.18 \\
12.68 \\
10.01\end{array}$ & $\begin{array}{l}0.0671 \\
0.0660 \\
0.0539 \\
0.0838 \\
0.0641 \\
0.0717 \\
0.0646 \\
0.0933 \\
0.1048 \\
0.0875 \\
0.0590 \\
0.0937 \\
0.0689 \\
0.0742\end{array}$ & $\begin{array}{l}1.0 \\
1.1 \\
2.5 \\
1.5 \\
1.8 \\
2.2 \\
1.1 \\
1.2 \\
1.6 \\
1.9 \\
2.0 \\
1.1 \\
2.4 \\
1.3\end{array}$ & $\begin{array}{l}55.1 \\
21.1 \\
60.5 \\
17.8 \\
35.2 \\
14.9 \\
30.4 \\
34.9 \\
29.2 \\
56.8 \\
18.1 \\
40.9 \\
75.8 \\
32.4\end{array}$ & $\begin{array}{r}1,165 \\
367 \\
1,164 \\
549 \\
860 \\
462 \\
640 \\
1,105 \\
1,068 \\
1,257 \\
987 \\
1,195 \\
1,087 \\
727\end{array}$ & $\begin{array}{l}0.067 \\
0.073 \\
0.135 \\
0.126 \\
0.115 \\
0.157 \\
0.071 \\
0.112 \\
0.168 \\
0.166 \\
0.118 \\
0.103 \\
0.165 \\
0.096\end{array}$ & $\begin{array}{r}3.792 \\
2.141 \\
3.637 \\
1.921 \\
.751 \\
1.324 \\
2.454 \\
3.637 \\
2.296 \\
2.308 \\
1.154 \\
2.328 \\
6.132 \\
2.404\end{array}$ & $\begin{array}{r}1,226 \\
400 \\
1,205 \\
1,045 \\
510 \\
785 \\
375 \\
1,214 \\
725 \\
420 \\
370 \\
1,149 \\
1,229 \\
1,255\end{array}$ & $\begin{array}{l}30.2 \\
28.9 \\
34.9 \\
30.3 \\
33.4 \\
31.4 \\
30.3 \\
29.4 \\
29.9 \\
31.2 \\
30.0 \\
29.0 \\
30.7 \\
29.9\end{array}$ & $\begin{array}{l}31.2 \\
31.7 \\
33.3 \\
31.6 \\
31.0 \\
32.6 \\
31.5 \\
29.9 \\
31.1 \\
31.5 \\
31.4 \\
29.1 \\
31.4 \\
30.0\end{array}$ & $\begin{array}{l}33.6 \\
36.3 \\
35.1 \\
34.3 \\
36.0 \\
36.4 \\
35.7 \\
33.5 \\
34.1 \\
35.2 \\
34.9 \\
34.8 \\
35.4 \\
33.9\end{array}$ & $\begin{array}{l}36.7 \\
37.1 \\
37.0 \\
37.3 \\
37.4 \\
36.9 \\
37.3 \\
37.5 \\
37.7 \\
37.6 \\
37.4\end{array}$ \\
\hline Mean & 20.46 & 19.69 & 12.17 & 0.0752 & 1.6 & 37.4 & 902 & 0.119 & 2.591 & 851 & 30.7 & 31.2 & 34.9 & 37.3 \\
\hline Standa & d error & & & & \pm 0.14 & \pm 4.9 & & $=0.010$ & $=0.338$ & & & & & \\
\hline
\end{tabular}


response was noted within an average of 13 and 15 seconds after termination of the exercise, for the higher and lower bath temperatures, respectively, the actual maximal increase, in excess of the resting level, also showing no real difference for the two experimental conditions (average of $1.162 \mathrm{ml}$. per $100 \mathrm{ml}$. limb volume for the higher bath temperature and $1.147 \mathrm{ml}$. for the lower). However, in every instance the control level was reached sooner at the higher bath temperature, an average of 453 seconds as compared with 851 seconds at the lower bath temperature. This difference was found to be statistically significant, with $\mathrm{p}<0.001$. Furthermore, when the total oxygen uptake, in excess of the resting level, was determined, it was less at the higher bath temperature than at the lower, except in one instance (N.D.). The difference between the two sets of figures (Table I) was found to be statistically significant, with a $\mathrm{p}<0.01$.

\section{DISCUSSION}

Examination of the data on blood flow and oxygen arteriovenous difference reveals that in all instances at the two bath temperatures the oxygen debt in the initial portion of the postexercise period was repaid both by a marked increase in blood flow and by a greater than normal extraction of oxygen from each ml. of blood (Figure 2). This combined response, which lasted for only two to three minutes, was then followed by a much longer period of augmentation of local circulation, associated with either a normal or an elevated oxygen content of venous blood. Such observations are not in accord with the findings of Quensel and Kramer (9) and of Love (10), who noted a substantial increase in oxygen content of the effluent venous blood immediately after termination of a period of tetanic or rhythmic contractions. It is possible that such a difference in results can be attributed to the use of aerobic exercise by these authors and anaerobic exercise in the present study.

In this investigation, the consistent finding at the lower muscle temperature and the occasional one at the higher, of smaller than control oxygen arteriovenous differences in the later portion of the postexercise period can be interpreted as indicating that during this interval the increase in blood flow was of greater magnitude than warranted for the satisfaction of the metabolic needs of the exercising muscles. Such a response could, in a sense, be considered an inefficient means for the repayment of the oxygen debt. At the same time, however, it is necessary to note that at the lower muscle temperature, the oxygen uptake figures, based on these smaller than control oxygen arteriovenous differences and the increased blood flow values, were still greater than those obtained at the higher muscle temperature in the same period. This would imply that part of the large and prolonged augmentation in local circulation existing in the later portion of the postexercise period at the lower muscle temperature was required for the repayment of the more marked oxygen debt incurred by the work. On the other hand, the average quantity of oxygen extracted from each $\mathrm{ml}$. of blood during the postexercise period was less than in the case of the higher muscle temperature.

As has already been mentioned, in all experiments the blood samples used in the calculation of oxygen arteriovenous difference were collected from a vein apparently draining deep tissues, primarily, muscle. However, since there was no accurate means of ascertaining whether or not such a vessel received tributaries from superficial veins distal to its subcutaneous location, it is necessary to consider the question of contamination of the deep venous blood sample and the possible effects this might have had on the results.

As pointed out in a previous paper (4), resting oxygen uptake figures at a bath temperature of $45^{\circ} \mathrm{C}$., based on oxygen determinations of venous blood obtained from superficial tissues, were smaller than those derived from samples collected from deep veins. It would be expected, therefore, that in this study, at the higher bath temperature the presence of superficial venous blood in the sample would have lowered the level of the theoretical resting oxygen uptake during the postexercise period, thus increasing the magnitude of the excess oxygen uptake elicited by the exercise. Since such a situation did not exist at the lower bath temperature (4), any error resulting from contamination of the blood sample would have tended to make the calculated difference between the postexercise oxygen uptakes for the two experimental conditions less than the true value. 
It is also of interest to point out that at the two bath temperatures, contamination of the venous sample might not have had the same effect on the contribution resulting from the one-half minute of arterial occlusion. In this respect it should be mentioned that at a bath temperature of $45^{\circ} \mathrm{C}$., with the cutaneous and subcutaneous vessels already almost fully dilated by the heat, only minimal vascular changes would be occurring in the skin and subcutaneous tissue during reactive hyperemia. As a result, the increased needs of these structures, produced by the period of anoxia, would have to be satisfied almost solely through the mechanism of extraction of oxygen from each $\mathrm{ml}$. of blood. Consequently, it would be expected that during reactive hyperemia, oxygen arteriovenous difference, and hence, oxygen uptake, based on blood from superficial tissues alone, would be greater than at the lower bath temperature, under which circumstances the cutaneous and subcutaneous vessels were still capable of dilating in this period. Therefore, any contamination of the deep blood sample would again tend to make the difference in calculated postexercise excess oxygen uptake at the two bath temperatures less than the true value.

Another factor which must be evaluated is the effect of the one-half minute period of arterial occlusion utilized during the work. In this regard it should be mentioned that at both bath temperatures, the changes in the various readings following termination of the physical effort and removal of the arterial occlusion pressure were a composite of the alterations resulting from the state of anoxia and the exercise, with the contribution of the former being relatively negligible because of the short period of arterial occlusion. Nevertheless, it is necessary to know whether or not the change due to anoxia alone was of equal magnitude at the two bath temperatures. Of interest in this respect is the observation in a previous study (5) that the oxygen repayment following a five minute period of arterial occlusion, in excess of the baseline, was significantly greater at a higher than at a lower tissue temperature. On the basis of such findings, it would be safe to assume that if there had been a difference in the response to the one-half minute of arterial occlusion at the two bath temperatures, this would have manifested itself in the form of an increase in the excess oxygen uptake at the higher level, thus making the calculated difference between this figure and the one obtained at the lower bath temperature less than the true value.

One must also consider the question of the blood trapped in the forearm with the sudden application of the arterial occlusion pressure, since as a result, a source of tissue oxygen was conceivably available during the period of anaerobic work. Although this possibility existed for both bath temperatures, one would expect a larger amount of blood to be found in the vascular tree at the higher level because of the marked vasodilatation and augmentation of blood flow produced by the heat. This could have been reflected in the repayment of a smaller oxygen debt in the postexercise period, thus tending to make the calculated difference between the postexercise excess oxygen uptake at the two bath temperatures greater.

That the above objection did not particularly apply to the present study is supported by the following points : First, the vasodilatation at the high bath temperature occurred primarily in the cutaneous and subcutaneous tissues, so that most of the increase in the volume of trapped blood was not available to the active muscles. Furthermore, it can be assumed that under both experimental conditions, as a result of the pumping action of the exercising muscles, there was a rapid movement of blood from the arterial tree into the venous system, where it was no longer utilizable as a source of tissue oxygen. Finally, by maintaining the stopcock to the catheter in the deep vein open during the entire period of work, drainage of blood out of the muscles was facilitated, thus reducing further the possibility of aerobic metabolism during the exercise. It is realized, of course, that this means was not available for all portions of the forearm, except insofar as blood from them was shunted into the cannulated vein, since this vessel, through its opening to the environment, now represented a focus of reduced peripheral resistance. Another supporting point for the view that the trapped blood was not an important source of oxygen is the finding in a previous study (5) that the oxygen debt incurred during the five minute period of arterial occlusion and repaid subsequently was significantly greater at the higher tissue temperature than at the lower.

On the basis of the data obtained in the pres- 
ent study, it can therefore be stated that artificially raising the temperature of the muscles of the forearm caused a reduction in the magnitude of the oxygen debt incurred during anaerobic work. Such a finding tends to support the belief that there are some beneficial effects from the "warming-up" exercises carried out by athletes preliminary to the actual work performance (11-13), a view which has recently been questioned (14).

\section{SUMMARY AND CONCLUSIONS}

Using venous occlusion plethysmography and studies of local oxygen arteriovenous difference, the effect of altering external temperature on oxygen uptake of the forearm musculature following anaerobic work was investigated in a series of 14 normal subjects.

1. It was found that at both the higher and lower muscle temperatures the oxygen debt incurred during anaerobic work was repaid in the early postexercise period by an increase in blood flow and by a greater than normal extraction of oxygen, and in the later and more protracted period, by an augmentation in circulation alone.

2. At the higher muscle temperature the blood flow response to the exercise was less marked than at the lower, but oxygen extraction per $\mathrm{ml}$. of blood was greater.

3. At the higher muscle temperature, the postexercise oxygen uptake was reduced, despite an increase in resting oxygen uptake.

These results tend to support the belief that there is some basis for the use of local heat preceding the exercise of limbs in physical medicine and for the "warming-up" procedure customarily practiced by athletes.

\section{ACKNOWLEDGMENT}

The authors wish to express their appreciation to Dr. Clara J. Fleischer and Mr. Alan Kahn for assistance in carrying out the experiment and to Dr. Edward E. Gordon for constructive criticism of the data.

\section{REFERENCES}

1. Grant, R. T. Observation on the blood circulation in voluntary muscle in man. Clin. Sci. 1938, 3, 157.
2. Barcroft, H., Dornhorst, A. C., McClatchey, H. M., and Tanner, J. M. On the blood flow through rhythmically contracting muscles before and during release of sympathetic vasoconstrictor tone. J. Physiol. (Lond.) 1952, 117, 391.

3. Patterson, G. C., and Shepherd, J. T. The effects of continuous infusions into the brachial artery of adenosine triphosphate, histamine and acetylcholine on the amount and rate of blood debt repayment following rhythmic exercise of the forearm muscles. Clin. Sci. 1954, 13, 85.

4. Abramson, D. I., Kahn, A., Tuck, S., Jr., Turman, G. A., Rejal, H., and Fleischer, C. J. Relationship between a range of tissue temperature and local oxygen uptake in the human forearm. I. Changes observed under resting conditions. J. clin. Invest. 1958, 37, 1031.

5. Abramson, D. I., Kahn, A., Rejal, H., Turman, G. A., Tuck, S., Jr., and Fleischer, C. J. Relationship between a range of tissue temperature and local oxygen uptake in the human forearm. II. Changes observed after arterial occlusion, in the period of reactive hyperemia. J. clin. Invest. 1958, 37, 1039.

6. Abramson, D. I. Vascular Responses in the Extremities of Man in Health and Disease. Chicago, University of Chicago Press, 1944, p. 56.

7. Mottram, R. F. The oxygen consumption of human skeletal muscle in vivo. J. Physiol. (Lond.) 1955, 128, 268.

8. Snedecor, G. W. Statistical Methods Applied to Experiments in Agriculture and Biology. Ames, Iowa, The Collegiate Press, Inc., 1956, pp. 49 and 73.

9. Quensel, W., and Kramer, K. Untersuchungen über den Muskelstoffwechsel des Warmblüters. II. Mitteilung. Die Sauerstoffaufnahme des Muskels während der tetanischen Kontraktion. Pflüg. Arch. ges. Physiol. 1938, 241, 698.

10. Love, A. H. G. The rate of blood flow and the oxygen saturation of the effluent blood following contraction of the muscles of the human forearm. Clin. Sci. 1955, 14, 275.

11. Asmussen, E., and Bøje, O. Body temperature and capacity for work. Acta physiol. scand. 1945, 10, 1.

12. Malarecki, I. Studies on physiological justification of application of so-called warming-up. Acta physiol. pol. 1954, 5, 543.

13. Nielsen, M. Die Regulation der Körpertemperatur bei Muskelarbeit. Skand. Arch. Physiol. 1938, 79, 193.

14. Karpovich, P. V., and Hale, C. J. Effect of warming-up upon physical performance. J. Amer. med. Ass. 1956, 162, 1117. 